\title{
Discursos sobre comportamento de risco à saúde e a moralização da vida cotidiana
}

\author{
Discourses about health risk behaviour \\ and the moralization of the everyday life
}

\author{
$M$ arcos Bagrichevsky ${ }^{1}$ \\ Luis David Castiel ${ }^{2}$ \\ Paulo Roberto Vasconcellos-Silva ${ }^{3}$ \\ Adriana Estevão ${ }^{1}$
}

\footnotetext{
${ }^{1}$ Centro de Educação Física eD esportos, Universidade Federal do Espírito Santo. Av. Fernando Ferrari 514, Goiabeiras. 29075-910 Vitória ES.

marcos_bagrichevsky@ yahoo.com.br

${ }^{2}$ Escola Nacional deSaúde Pública Sérgio Arouca, Fundação Oswaldo Cruz.

${ }^{3}$ Laboratório delnovações TerapêuticasEducação e Bioprodutos, Instituto Oswaldo Cruz, Fundação Oswaldo Cruz.
}

Abstract The text analyses critically the polarity between discourses about healthy life styles and the sedentariness in the context of new technologies for health information research and dissemination. We argue that the techno-scientific rationality has grown an 'economy of trues' which, on the perspective of conducting to safe life styles, has prescribed a normative ideal of self discipline which tends to generate distress and consumerism of artifacts of burning calories. In the hege monic production of systems of truth, sedentariness has been seen as a kind of unhealthy behavior that is ranked as moral failure. Emphasis is given about themultiplediscourses embracing life styles and risk, taken as biopolitics devices imbricated in the communication processes in health, which has to be lightened up for their ethics and politics implications. The spectacularization of life styles associated to the consumption and the production of narratives that have badly influenced our culture, making bigger the distance of a socially possible notion of health. We discussed the regulatory essence of such a symbolic referencein the construction of knowledgesystems that have been ( $r e)$ defined what is to be healthy, normal and unhealthy.

Key words Risk behavior, Sedentarism, Lifestyle, $M$ oralization of health, $\mathrm{H}$ ealth information
Resumo 0 texto aborda criticamente a polaridade entre discursos sobre estilos de vida saudáveis e sedentarismo no contexto dos novos recursos tecnológicos de busca e disseminação de informações em saúde. Argumenta-se que a racionalidade tecnocientífica contemporânea fez emergir uma "economia das verdades" que, na perspectiva de conduzir a estilos de vida seguros, tem prescrito um ideário normativo de autodisciplina ge rador deangústias ede consumo deartefatos agenciadores de gastos calóricos. $\mathrm{Na}$ produção hege mônica desses regimes de verdade, o sedentarismo seapresenta como conduta de risco à saúde, equivalendo à falência moral e inaceitável falta de cuidado consigo. Enfatiza-se que a profusão de discursos sobre estilos de vida e risco, tomados como di spositivos biopolíticos imbricadosnos processos comunicacionais em saúde, merece foco por suas implicações éticas e políticas. A espetacularização de modos de vida associados ao consumo ea produção de narrativas que influenciam perversamentenossa cultura têm nos distanciado deuma noção de saúde socialmente possível. Discute-se, enfim, a essência reguladora detais referentes simbólicos na construção desistemas de conhecimento que vêm (re) definindo o que é ser saudável, normal, doente.

Palavras-chave Comportamento de risco, Sedentarismo, Estilo de vida, M oralização da saúde, Informação em saúde 


\section{Introdução}

Discursos que associam determinados comportamentos humanos aos chamados fatores de risco à saúdevigoram em produçõescientíficas no campo biomédico já faz algum tempo ${ }^{1}$. Entretanto, tem havido nos últimos anos uma ampliação do leque de posturas consideradas insalubres nesses estudos que, de certo modo, vem tomando de assal to as subjetividades da vida cotidiana ${ }^{2}$.

O sedentarismo - espécie de metáfora pósmoderna empregada para designar indolência, preguiça euma inaceitável falta decuidado consigo próprio - com frequência figura nas pesquisas como um desses comportamentos que remete à falência moral das pessoas ${ }^{3}$ e parece se autojustificar no bojo de tantos outros problemas graves da saúde populacional em países subdesenvolvidos e desiguais como o Brasil, por exemplo.

Os argumentos arrolados em estudos epidemiológicos acerca da antinomia "sedentarismo/ estilo de vida saudável" trazem à tona estilos de pensamento empenhados no embate ideológico pela soberania da produção dos regimes de verdade $^{4-6}$, cujos desdobramentos e interesses em jogo, sabidamente, extrapolam a própria arena científica. Quando incorporado em investigações sobre o mapeamento de agravos à saúde, fica subsumido o aumento do grau de relevância desse tipo de categorização em detrimento de outras questões a serem consideradas. De certa maneira, esse empobrecimento epistemológico já vem sendo criticado por analistas do campo $0^{7,8} \mathrm{em}$ função da epidemiologia moderna estar se distanciando progressivamente das preocupações sanitárias coletivas de sua origem histórica, pel o fato de adotar perspectivas de investigação mais afeitas ao trato individualista dos fenômenos.

Supondo queo combate ao sedentarismo seja realmente um objetivo plausível para as preocupações em saúde coletiva, como fazêlo sem estigmatizar as pessoas classificadas como sedentárias? A categoria "sedentário" - que tem sido legitimada nos estudos com base em critérios de gastos calóricos mínimos por dia obtidos através de atividade física voluntária e/ou recreativa - seria "aplicável", por exemplo, aos operários da construção civil cujas jornadas diárias árduas, invariavelmente desprovidas de horas de lazer (por falta de condições financeiras ou pelo cansaço físico proveniente do trabal ho exaustivo), incidem de modo deletério sobre seus corpos? Se justaposta aos preceitos definidores do sedentarismo, a atividade física laboral que tem levado milhares de cortadores de cana (boa parte, migrantes de regi- ões longínquas do país) à morte nas colheitas do interior de São Paulo em troca de remunerações irrisórias ${ }^{9}$ deveria ser considerada fator de proteção ou fator de risco à saúde?

Sob essa ótica, não apenas a classificação se revela inapropriada, mas também a preconização das mudanças de comportamento (estilos de vida), inferida como uma quase panacéia remediadora em investigações epidemiológicas que advogam a relevância do suposto problema. $\mathrm{Pe}$ $\mathrm{draz}^{10}$ corrobora tais questionamentos quando sinaliza que estudos antropológicos e sociológicos já realizados no campo sanitário mostraram que a distância entre pobres e ricos (estratificações socioeconômicas) se amplia de forma tanto mais definida, quanto mais agudamente se expressam as "polaridades corporais" nos contextos populacionais analisados.

Torna-secada vez mais reconhecível a influência nuclear da epidemiologia nas perspectivas que governam a organização das práticas sanitárias contemporâneas, amiúde impulsionada pela superexposição acrítica de textos especialistas impregnados de juízos de valor e à distância de seus contextos ${ }^{7}$.

Não são raros nem inócuos os efeitos dessa ausência de criticidade. A renúncia ao rigor filosófico na análise de alguns conceitos centrais à institucionalização de práticas promotoras de saúde tem produzido noções que se limitam às visões do indivíduo isolado de sua cultura e de seu potencial de interferência nas agendas públicas. Decerto, tais ênfases na ação individual promovem autonomia na forma, embora se mostrem despolitizadoras na essência. Elas apontam para a necessidade de se relativizar a ênfase acerca do papel da responsabilização pessoal na busca de saúde pelo sujeitos, considerando o engessamento ou a lentidão nas mudanças macroestruturais ensejadas pelas políticas públicas que pretendem, em termossucintos, promover a saúde em prol de superar iniquidades sociais e que deveriam, sob o ponto de vista ético, ter maior parcela de contribuição nesse processo.

Levando em conta essas premissas, parece prudente então colocar sob suspeita a retórica superlativa que recai sobre condutas cotidianas, tomadas como insalubres ou "perigosas" em interpretações epidemiológicas e colocadas à vista pelos meios de comunicação de massa5,11. Inclusive, já há uma gama extensa de autores críticos na literatura que considera essa estratégia temerária, uma vez que tem se convertido em um imperativo moralizante ${ }^{1,3,12}$, gerador de repercussões significativas na vida contemporânea que 
ditam modos subjetivos de nos conduzirmos, nos alimentarmos, nos relacionarmos e interferem na conformação de nossas crenças e valores culturais históricos.

Esses discursos são responsáveis, no limite, por um efeito adverso que traz uma dimensão persecutória aos indivíduos diante das propostas de promoção da saúde baseadas em modelos comportamentais enfeixados pela idéia do estilo de vida saudável e em estratégias que suscitam a culpabilização preventiva daqueles que se expõem aos riscos tecnicamente predimensionados ${ }^{2}$.

Cada vez mais somos alardeados sobre a liberdade de opção e de escolha para conduzir nossa saúde e nossas vidas, mediante a gestão das informações sobre todos os riscos estudados, medidos e nomeados. As mensagens persuasivas dessa biopolítica sanitária ${ }^{13}$, disseminadas na fronteira virtual entre ciência, mídia e mercado, emergem numa era marcada pelo concomitante crescimento de desigual dades sociais e fluxos de informação, conformando um novo fenômeno econômico-cultural pós-moderno: 0 agravamento moral do sedentarismo como pecado contemporâneo.

É, portanto, a força retórica da idéia de erro ou desvio de conduta que leva a prejuízos para si e para outros (por exemplo, na oneração dos sistemas de saúde) associada ao sedentarismo que nos possibilita explorar adiante alguns ele mentos situados ao redor da questão nuclear deste trabalho, sinalizada desde o título.

Racionalidade tecnocientífica ediscursos anteci patórios de riscos à saúde

Examinar os sentidos constituídos nessa lógica sanitária- sutil eprofundamenteentremeada nos discursos sobre os riscos - requer que se considere, a um só tempo, seu entrelaçamento à perspectiva emblemática vigente do predomínio da racionalidade biotecnocientífica produtora de ideologias e políticas homogeneizantes ${ }^{2}$, bem como os efeitos dos processos de globalização que têm tornado a vida coletiva fragilizada, insegura e susceptível à mercantilização do corpo e da própria saúde. Segundo Bauman ${ }^{14}$, esses aspectos vêm definindo as bases conceituais dos valores da dita condição humana.

O bserva-sena atualidade a disseminação crescente de regras prescritivas a favor do envolvimento com (auto)disciplina e normas de comportamento na busca de se promover uma "boa saúde", sem que, necessariamente, percebamos emergir, na mesma medida, discussões acerca do significado disso.

Em tempos de um capitalismo neoliberal voraz, é preciso lembrar que ciência e tecnologia representam signos emblemáticos nas ditas sociedades globalizadas, justamente porque se tornaram poderosas forças estratégicas, responsáveis pelo desencadeamento de grandes transformações na saúde, no ambiente físico e nas diversas esferas macro e micropolíticas da vida em coletividade ${ }^{15,16}$.

Por esta e outras razões, analistas sociais dentro e fora do campo das ciências da saúde consideram preocupante 0 exponencial crescimento do discurso "preventivista-antecipatório" que contemporaneamente tem impregnado 0 norteamento de muitas áreas de pesquisa, como por exemplo, a epidemiologia genética e as biomedicinas moleculares ${ }^{17,18}$.

Diferentes correntes técnicas e acadêmicas vêm buscando desvelar (segundo argumentações próprias, amiúde tornadas públicas pelos mass media) caminhos e procedimentos de evitação de agravos à saúde dos indivíduos. Proliferam acenos de redução de incertezas e riscos pela via da potencialização da eficiência/eficácia de processos de curas/terapias em escala populacional, agrupados em torno da defesa incondicional de um discurso empiricista que, embora nos pareça unívoco, quando observado de fora, deixa à mostra ambivalências ${ }^{4,5}$.

Tais promessas não levam em conta as injunções sociopolíticas, culturais eeconômicas de fenômenos complexos que se replicam em terrenos que Ihes escapam à observação, posto que esta se contenta com a superfície das aparências na dimensão mais acessível às perspectivas acríticas. Ou seja, há em curso vasta disseminação de um rol de soluções simplistas para questões complexas, como o cuidado com a saúde. $\mathrm{Na}$ farta produção eexposição dessas ofertas à sociedade, não édifícil entrever indícios de uma orientação reducionista governada por interesses ideológicos e de mercado ${ }^{19,20}$.

De fato, diferentes observadores ressaltam que as supostas garantias retóricas projetadas por essa racionalidade preventivista não se traduzem, obrigatoriamente, em tranquilidade, certeza, eficácia e confiança ou ensejam formas mais adequadas de lidar contextualmente com questões da saúde no cotidiano. Por não perceberem as numerosas particularidades constituintes do homem contemporâneo, produzem discursos reducionistas geradores de angústia, ansiedade e sofrimento ${ }^{1}$. 
Tais repercussões ganham um sentido especial no processo saúde/doença/cuidado, se o assumirmos como expressão dos modos possíveis de gerenciar (e até resistir a) desejos e expectativas que se apresentam a nós na atualidade, como imperativos inal cançáveis de um mundo contraditório. Essa paradoxalidade diz respeito, por exemplo, à profusão de estímulos de toda ordem dirigidos ao consumo desenfreado e em massa, de um lado, enquanto que, de outro, substancial parte da população na chamada "aldeia global" continua depauperada e à margem de políticas sociais dignas ${ }^{14}$.

Assim, são nessas ambiências concretas do cotidiano - espaços de redes sócio-históricas onde estamos inseridos - que emergem "verdades" singulares, muitas vezes intransferíveis ou pouco afeitas a proposições científicas generalizantes. Singularidades essas que podem ser diluídas ou até aniquiladas por hiatos (por vezes, abissais) entre o que se pressupõe no plano dos discursos antecipatórios sobre o risco, ofertados em larga escala, eaquilo que ocorre pontualmente no mundo possível daqueles para quem essas mensagens são dirigidas ${ }^{21}$.

Entretanto, essa apreciação crítica que colocamos em relevo propositalmente não invalida ou nega a necessidade de se considerar e incluir saberes epidemiológi cos eclínicos e práticas inovadoras nos diferentes campos profissionais atuantes na saúde coletiva, uma vez que têm importância e utilidadenotórias, reconhecidas há muito tempo. Seria incoerente fazêlo.

Considerando a argumentação até aqui reunida, pretende-se, então, sinalizar a insuficiência dos fundamentos regentes daquilo que chamaremos de protocolos discursivos diagnósticopreventivos, sejam eles dirigidos aos indivíduos ou aos coletivos, por suas pretensões universalizantes - fato que preocupa, uma vez que os mesmos têm guiado, hegemonicamente, formas de pensar e de intervir sobre os processos saúde/ doença/cuidado.

A apreensão justifica-se, em primeiro lugar, porque tais estratégias podem suscitar, de maneira indesejada e ambígua, efeitos colaterais iatrogênicos em diferentes perspectivas, conforme apontam alguns estudos ${ }^{22-24}$. Em segundo, porque geralmente esses protocolos não tangenciam os (muitos) contextos desiguais de cada realidade populacional para os quais são difundidos seus preceitos basilares. Há uma vasta literatura na América Latina eno Brasil quevem identificando resistências, desvios e lacunas em relação a tal normalização impositiva ${ }^{25,26}$.
Desde já, é providencial anunciar que o entendimento referenteà expressão protocolos discursivos diagnóstico-preventivos traduz-se por ações/técnicas/estratégias retóricas que, tomando como base a racionalidade científica técnicoinstrumental, têm buscado padronizar uma síntese universal de fenômenos biológicos e socioculturais, encolhendo suas nuances diferenciadoras (protocolo) através de descrições genéricas de determinado contexto processual (diagnóstico) para, em seguida, propor "medidas solucionadoras" que, supostamente, evitariam ou antecipariam um dado problema (prevenção).

É nessa perspectiva quese conformam os discursos antecipatórios de riscos à saúde. Eles são produzidos e colocados em circulação massiva por diferentes atores sociais e meios, a partir de uma ampla rede de microdeci sões produtora de ideologias $4,8,20$. Rede na qual se posicionam, com diferentes poderes deci sórios e interesses, os sujeitos e suas subjetividades. Os protocolos discursivos, com vistas a receptores imaginados, são construídos justamente nessa ambiência interativa de forças em desequilíbrio.

Existe uma hipótese de que a noção de risco vem substituindo a idéia de norma social, como forma predominante na cultura ocidental vigente para se pensar o poder sobre a ação humana. 0 conceito derisco prevalecenuma sociedadecom traços hedonistas, na qual há uma margem pequena de autonomia individual em relação à escolha (possível) de estilos devida ${ }^{21}$. Trata-se, pois, da molecularização dos mecanismos de controle dos indivíduos, que se tornaram mais adequados às relações de forças e modos de organização da sociedade contemporânea, por suas sutilezas persuasivas e permeáveis, capilarizadas, quase invisíveis ${ }^{27,28}$.

$\operatorname{Vaz}^{29}$ assinala um exemplo na dimensão da saúde, enfatizando que o "cuidado" é ocasião de prudência individual pós-moderna: É sugestivo que emerjam aqui e ali propostas, como aconteceu na Inglaterra, de não prover assistência pública de saúde para fumantes e obesos. Embora facilmente criticáveis como tentativa de reduzir custos e culpar a vítima, pelo mero fato de serem concebidas, anunciam o nascimento de um novo contrato entreEstado eindivíduos: segurança para quem éprudente e maximiza seu estilo de vida [grifo nosso]. 0 resto são os monstros, aquelesqueestão aquém da humanidade e da possibilidade de correção.

A perspectiva de conduzir as pessoas a estilos devida idealizados (saudáveis ou ativos) só pode ser avaliada, de fato, no momento mesmo de efetivação dos protocolos preconizados - quan- 
do, ondeeseforem alcançados. Nesse caso, podeseobservar a complexa relação entre o queé produzido ideologicamente e a maneira circunstancial através da qual as pessoas são interpeladas, percebem, interpretam e incorporam tais propostas ao mundo da práxis.

Discursos com pretensões de eficácia, moldados por relações de saber/poder, pela relevância que têm assumido no agendamento de questões públicas, passaram a exercer a força de referentes simbólicos na construção de identidadese relações sociais, sistemas de conhecimento e de valores societários $s^{30,31}$.

Setais discursividades reproduzem modos de pensar, escrever e mostrar algo, e têm a pretensão de intervir sobre diferentes esferas da vida humana, torna-se necessário não apenas situálas nos momentos históricos e contextos concre tos de sua elaboração - de forma a analisar mais detidamentea lógica engendrada, eminentemente subjetiva e complexa - mas, também, perscrutar como se movem os distintos sujeitos nesses modos de produção e circulação. Cabe, igualmente, investigar as razões pelas quais se legitimam, são negadas, refeitas ou assumem novos sentidos, nos espaços onde se fazem presentes.

Discursos sobre riscos à saúde são constructos de caráter normativo e estão, inapel avelmente, vinculados a diferentes interesses. Constituem-se, de modo explícito ou não, a partir de de finições do que é ser humano, do tipo de socie dade que se almeja e as maneiras de al can çá-la $a^{32}$.

Sibilia $a^{33}$ enfatiza que a partir da redefinição dos "padrões" de normalidadee, portanto, da nova dinâmica de biopoder ligado à lógica do consumo no mercado capitalista "globalizado", a doença é redefinida como um erro na programação [denosso código genético] que deve ser corrigido, para reativar a saúde do corpo e da alma (tanto individuais quanto sociais). Não é mais necessário localizar uma origem patológica para os sintomas: basta apenas conferir sua distância com relação ao padrão normal.

A descrição rigorosa e exaustiva da etiologia classificatória de fenômenos orgânicos não visa apenas ampliar a capacidade de compreensão sobre o processo saúde/doença das populações. Possui, na mesma medida, um caráter de iniciação na verdade das coisas, que divide o mundo entre os que sabem (os especialistas) e os que não sabem (a população leiga) ${ }^{34,35}$. Na perspectiva de emergência dessa economia de verdade, 0 conceito de risco surge como uma categoria de "pré-doença", obviamente, passível de intervenção pelos experts.
Diferentes autores ${ }^{13,29,35,36}$ destacam, criticamente, a visível profusão de discursos sobre riscos com fins culpabilizantes, também em estratégias de promoção da saúde, educação em saúde, marketing social, participação comunitária e colaboração intersetorial em saúde. E, apesar das mensagens estarem, em tese, ligadas à prevenção deagravos populacionais, argumenta-sequenem sempre se observam efeitos significativos na redução dos problemas a que se propõem sanar.

Não obstante o desejo (louvável, diga-se de passagem) de implementar ações e idéias para minimizar questões emblemáticas em saúde coletiva (por exemplo, as doenças que [re]emergem em função dos quadros de iniquidade socioeconômica do país), várias têm sido as análises que identificam nesse movimento campanhista uma crença conservadora, iluminista, com fortetraço moralizante e estreitas ligações com o mercado. Nessa linha de raciocínio, Campos ${ }^{37}$ reconhece tal característica em uma dessas estratégias: " [...] a perspectiva dominante de educação em saúde na atenção médico sanitária é profundamente autoritária e prescritiva, quer na clínica, quer nos programas de saúde pública".

Atividadefísica, anti-sedentarismo e capital corporal: simbiose discursiva na cruzada pela (des)moralização de comportamentos (in)salubres

M ais recentemente, algumas políticas de saúde no Brasil situadas dentro dessa concepção neohigienista vêm divulgando a idéia de se utilizar/ prescrever práticas sistematizadas de atividade física (AF) como forma alternativa de combateà morbimortalidade das chamadas doenças crônico-degenerativas, mas, principalmente, como dispositivo discursivo para exorcizar o pecado contemporâneo do homem moderno chamado de sedentarismo. Os argumentos dessa cruzada saudável antissedentarismo apoiam-se, sobretudo, nas teorias etiológicas do estilo de vida e em resultados estatísticos produzidos por pesquisas epidemiológicas ${ }^{38}$.

Nesse sentido, várias práticas corporais que outrora ganhavam sentido nas esquinas e comunidades dos bairros, em função da identidadecultural gregária degrupos epessoas edo prazer que proporcionavam a cada um deles, perderam espaço na vida contemporânea (como por exemplo, o futebol de várzea, entre tantas outras atividades coletivas lúdico-esportivas, praticadas em praças e espaços públicos similares). 
Cabe afirmar que, na ótica presente de algumas agendas de governo, a inclusão de (programas de) AF como ação de política pública apare ce, então, como "remédio amargo", mas necessário, para combater males e agravos que, conforme anunciam os discursos oficiais, contabilizam gastos inaceitáveis para os cofres públicos. Há uma clara tentativa de se estabelecer convencimento argumentativo por meio de inferências causais reducionistas, ancorado a priori em uma lógica econômica que, curiosamente, sobrepõee antecede as próprias preocupações com a saúde da população.

Parece prudente tecer aqui outra ressalva. É preciso deixar claro que não se está negando os jáconhecidos benefícios quea prática daAF pode proporcionar ao organismo, desde que, obviamente, seja conduzida respeitando os limites individuais das pessoas e os contextos nos quais podeser realizada. Longe disso, a questão central reclamada éa expropriação dos valores e significados das práticas da cultura corporal na atualidade, que passaram a povoar o imaginário social denossas col etividades, atravessados por uma perspectiva impositiva, medicalizadora, culpabilizante, agenciadora do contingente de gastos calóricos para evitação de riscos à saúde ${ }^{13,39}$.

E, nesse caso, é desprezada a possibilidade de se reconhecer e valorizar as diferentes práticas corporais como "artes de fazer" ou "modos de estar" na vida, com vínculos explícitos em ambiências deinterações socioculturais, como produtoras de satisfação pessoal, de prazer sem obrigatoriedade, que levam em conta as transformações possíveis de se obter no corpo de cada um de maneira singular ${ }^{40,41}$.

$\mathrm{Na}$ evidentetentativa de referen dar estrategicamente essa noção de comportamentos de ris$c o$, universalizando-a entre nós como uma verdade científica, boa parte dos estudos biomédicos tem disseminado a percepção de que a diminuição da prática de atividade física diária das pessoas deve ser considerada um desses comportamentos danosos à saúde.

De acordo com Fraga ${ }^{13}$, a expressão sedentário era empregada até pouco tempo depois do período da Revolução Industrial como antônimo de nômade (pessoas ou grupos que não fixavam residência, fato que para tal movimento era desinteressante, pois estas não podiam ser esquadrinhadas pela nova ordem econômica da época que começava a ser estabelecida com a emergência do modelo das cidades industriais ocidental izadas). A conotação que o termo comporta hoje pode ser considerada uma apropria- ção linguística neo-higienista, com finsculpabilizantes. Sedentário, nessa ótica, éal guém quepode ser responsabilizado por seu desleixo quanto à própria aparência física e saúde, que constantemente está em falta com o rigor prescritivo dos comportamentos saudáveis, entre os quais está incluída a prática de atividades físicas, tomada como afirmação individual de bom caráter.

Le Breton ${ }^{42}$ confirma o fato de que tais interpretações são atribuições moralistas da sociedade, que tem sido incompetente em sua função antropológica de orientação da existência humana, na qual tudo vem se tornando provisório e os limites e valores culturais coletivos perderam sua legitimidade. Sob esse panorama, 0 autor sublinha a contraditória emergência das práticas associadas ao risco-aventura e aos esportes radicais, que guardam uma lógica inversa àquela que categoriza o corpo sedentário como indolente, passivo. Distinguido pela firmeza de caráter eretidão moral, o sujeito (fisicamente) "ativo" exibiria uma marca valorativa no ato de arriscar voluntariamente sua própria integridade e saúde, ao sabor de intempéries ambientais extremas, às custas do sofrimento e dos limites orgânicos do corpo, para demonstrar uma capacidade íntima de olhar a morte de frente sem fraquejar.

Por outro lado, parte da ampliação desse panorama problemático que encarcera o sedentário em sua própria negatividade existencial pode ser atribuída às mensagens midiáticas difundidas que insinuam a obtenção de uma "saúde positiva" através do consumo de produtos (alimentos dietéticos, pomadas, equipamentos, remédios, etc.) e serviços (academias de ginástica, tratamentos e cirurgias estéticas, etc.) de toda ordem, disponíveis no mercado. Utiliza-se para isso um bombardeio informativo-publicitário com persuasivas estratégias psíquicas, afetivas e morais. Trata-se da maneira de mostrar e falar de um corpo outro, distintamente vivido, investido, pelos mais diversos meios de controle, incorporado por diferentes ritmos de produção e consumo, de prazer e de dor ${ }^{43}$.

A exacerbação dos cuidados de si no plano da saúde individual/privada, a proliferação de uma ética volátil da beleza ocidentalizada e dos predicados corporais, delineados pelo gosto estético conceitual contemporâneo, vêm setornando cada vez mais um imperativo público e, consequentemente, preocupação central na vida de um número crescente de pessoas ${ }^{19,44}$. 0 investimento no individualismo é um dos tópicos ético-políticos recorrentes na discussão sobre o que nos separa da modernidade ${ }^{45}$. 
Vale lembrar que muitas pessoas têm se disponibilizado à submissão de sofrimentos e sacrifícios em meio a esse padrão de discursividade, para ganhar longevidade, reparar imperfeições estéticas, despistar as marcas do tempo sobreseus corpos e, no limite, procurar evitar a morte ${ }^{46}$. Muito embora, para isso, se exponham invariavelmente, sem prévios esclarecimentos de que podem sucumbir a graves problemas de saúde (e, algumas vezes, até morrer), nas tentativas de alcançar mudanças corporais, rotineiramente incitadas e naturalizadas por diferentes estraté gias midiáticas, impulsionadas pela indústria da estética e do fitness.

Constituem exemplos ressonantes sugestivos desses modos iatrogênicos de lidar com o corpo e a saúde (tornados públicos recentemente) a suscetibilidade entre os jovens aos efeitos deleté rios do uso maciço de esteróides anabolizantes e inibidores de apetite e da ampliação de ocorrências clínicas como choques anafiláticos, comas e paradas cardíacas durante cirurgias de lipoaspiração, em função do crescimento exponencial desse tipo de intervenção ${ }^{47}$.

Entretanto, não é o caso de propor aqui uma análise maniqueísta sobre decisões de se desfrutar ou não do exercício salutar de liberdade em relação à própria saúde, mas de enfatizar a ne cessidade de se reexaminar as normas universais prescritivas, imbricadas em discursos hegemônicos sobre AF e sedentarismo. É fundamental problematizar os lugares discursivos de onde partem e suas redes de interesses que, ao povoarem o que é deles mostrado em público, os tornam referências atrativas para determinados grupos de receptores imagi nados.

Cabe também considerar que outras referências sociodiscursivas são, de certo modo, marginalizadas ou descartadas na grande circulação dos veículos comunicacionais, uma vez que poderiam representar alternativas mais adequadas de balizamento para escolhas pessoais e coletivas quanto aos modos de viver elidar com a própria saúde. Sem dúvida, essejogo desigual de tensões em disputa interfere subjetivamentenas decisões acerca do que (e quanto) comemos; se devemos ou não fumar, ingerir bebidas alcoólicas, fazer exercícios físicos, entre outras práticas cotidianas. Nas palavras de Vaz et al. ${ }^{5}$, "é urgente, pois, refletir sobre que tipo de vida está sendo construído por esses alertas sobre os perigos que estariam à espreita em nossos hábitos e que pode[ria]m se concretizar num futuro remoto".

Todavia, ébem sabido quetais fronteiras éticas têm esbarrado em bases movediças, débeis, no mundo globalizado contemporâneo. Lupton ${ }^{1}$, inclusive, advertequeo preço pago pela eventual defesa de uma postura de resistência ante aos ditames imperativos da saúde pode ser catastrófico, levando muitas vezes à estigmatização social das pessoas eà fragilização dos laços identitários entre pares, em variados espaços da vida diária, das relações de trabalho àquelas do mundo do afeto.

\section{Considerações finais: a difusão do estilo de vida saudável como dispositivo biopolítico no campo sanitário}

Diversos trabalhos têm demonstrado preocupações com a orientação disciplinadora do preceituário da vida ativa, que se pretende saudável 13,19,44,48. Tal orientação, norteada por um ideal deconstituição física, se mostra cada vez mais cercada por implicações de essência moral - à "sem-vergonhice" do sedentarismo deve-se antepor a virtuosa opção por um comportamento salutar socialmente idealizado.

Ser saudável, na atualidade, deixou de significar um modo simbólico através do qual se buscaria alcançar o bem-estar e tornou-se a própria finalidade de nossa existência, uma meta persecutória almejada custe o que custar. I mbricadas nessa dimensão retórica, expressões como estilo de vida saudável/ativo e comportamento de risco/sedentarismo, com frequência assumem os respectivos sentidos deuma identidadenormal e patológica ${ }^{49}$, nos assujeitando ${ }^{50}$ cada vez mais nessas práticas discursivas.

Como parece a Foucault ${ }^{51}$, a vida biológica é um evento político, cujo controletem se mostrado fundamental para as relações hegemônicas entre Estado e população, já que através do exercício das técnicas de poder sobre o corpo individual (regulamentação de normas edisciplinas de comportamento) pode-se chegar ao controle do corpo social.

Vistas sob essa perspectiva, estratégias de educação em saúde e promoção da saúde que enfatizam mudanças de comportamentos ${ }^{2,13,35}$ podem representar contribuições ímpares para o exercício do biopoder, porque envolvem disciplina e normas de conduta que têm por objetivo promover uma "boa saúde" e interferir nas escoIhas individuais, informando sobre como alcançar os estilos de vida saudáveis.

Sibilia ${ }^{33}$ argumenta que nossa atual sociedade, atravessada pela informação digital de inspiração imaterial, situa os atributos biológicos de nossa herança genética (DNA) justamentena in- 
tersecção entre corpo individual e corpo da espé cie, como um alvo privilegiado tanto das biopolíticas que convergem para a população humana, quanto das tecnologias específicas de mode lagem subjetiva.

Tais preocupações analíticas vêm permeando um espectro de grande envergadura dentre as possibilidades investigativas temáticas na área da saúde. Por conseguinte, podem suscitar maneiras potencialmente promissoras para descortinar esse intrincado quadro normativo de ações científico-racionais que têm instituído retóricas, posturas e estratégias (também) no campo sanitário; subsidiado a formulação de políticas públicas e impulsionado (in) diretamente a lucratividade degrandes conglomerados transnacionais do complexo médico industrial e do mercado da cosmética, da moda, do fitness e do entretenimento, movimentando cifras inimagináveis.

A despeito do prestígio que goza junto àsinstâncias oficiais de ciência e tecnologia, o tema da biopolítica informacional em saúde $e^{13,52}$ merece atenção por suas densas e preocupantes implicações na vida humana, nesseinício do século XXI.

0 enredamento dessas singularidades possíveis de serem exploradas e reinterpretadas à luz da aparente polaridade entre preconização do estilo de vida saudável e demonização do sedentarismo (e do sedentário) foi a questão maior que nos impeliu a situá-la como problemática relevante na presente reflexão. Sobretudo, levando em conta o contexto social em que estamos inse ridos, no qual grandes velocidades de disseminação de novos protocolos discursivos e de uso das informações em saúde vêm nos impondo renováveis e mutantes modelos tecnológicos como a Internet, cujos conteúdos, muitas vezes, aportam formas acríticas ebanalizadas de interpretar acontecimentos expressivos de nossas vidas.

Do mesmo modo, outras tecnologias de informação e comunicação (TIC) têm determinado desigualdades de ritmos e de oportunidades de acesso a tais referenciais, uma vez que dependem, obviamente, das disponibilidades ofertadas pelo mercado e da dimensão econômica e cultural desse entorno.

0 alcance e complexidade das questões que envolvem inúmeras esferas societárias exigem que sejam revistos com urgência os fundamentos epistemológicos, políticos e éticos dos processos comunicacionais em saúde vigentes. Pela importância do tema, também os estudiosos da mídia vêm se esforçando para construir uma gramática crítica do excesso, da espetacularização e da fabricação de imagens e narrativas que atravessam esse campo ${ }^{15,21}$.

Canclini ${ }^{26}$ corrobora essa preocupação ao afirmar com ironia que nos encontramos hoje na "sociedade do desconhecimento", marcada pela acumulação deinformações efêmeras e pouco importantes, que têm ocupado o papel da comunicação pública. Análises dessa natureza sugerem às instâncias da gestão de políticas públicas indicativos para reexaminar os processos de construção e disseminação de promessas falaciosas, queatingem perversamentea convivência em coletividade e nos distanciam de um cotidiano cultural da saúde mais humanizado.

Fortemente entrel açadaa essas produções subjetivas, a aversão aos chamados comportamentos de risco à saúde, entre os quais figura o sedentarismo, se constitui cada vez mais na obrigação moral predominante articulada à expertise controladora tecnocientífica. Tal panorama alimenta 0 ambiente de hipervigilância e de suspeita que vigora em vários níveis e aspectos da vida atual ${ }^{53}$.

A pesar da intensificação de propostas circulantes nos meios de comunicação de massa acerca de estilos de vida modelares, ainda há linhas de fuga ${ }^{54}$ na lida com a saúde que podem tomar formas mais compatíveis com o referencial da história de nossas vidas e em conformidade com um outro ethos. Até porque há tantos modos possíveis de ser saudável quanto de ser humano $0^{55}$. 


\section{Colaboradores}

Todos os autores desenvolveram e sistematizaram conjuntamente todas as partes do texto. A redação final coube a M Bagrichevsky.

\section{Agradecimentos}

Ao CN Pq e à FAPESB, pelo apoio financeiro aos projetos deinvestigação em curso. Desejamos expressar também nossa sincera gratidão ao pare cerista anônimo pelos comentários cuidadosose construtivos que ajudaram a melhorar a qualidade do texto.

\section{Referências}

1. Lupton D. The imperative of health: public health and the regulated body. London: Sage; 1995.

2. Castiel LD, Alvarez-Dardet C. A saúde persecutória: os limites da responsabilidade. Rio de Janeiro: Fiocruz; 2007.

3. Buchanan D. Moral reasoning as a model for health promotion. Soc Sci M ed 2006; 63:2715-2726.

4. Lupton D. Risk. London: Routledge; 1999.

5. Vaz P, Pombo M, Fantinato M, Pecly G. O fato de risco na mídia. Interface (Botucatu) 2007; 11:145-53.

6. Pedraz MV. La construcción de una ética médicodeportiva de sujeción: el cuerpo preso de la vida saludable. Salud Pública M ex 2007; 49:71-78.

7. Ayres JRCM. Sobre o risco: para compreender a epidemiologia. 2a ed. São Paulo: Hucitec; 2002.

8. Almeida Filho N. A clínica e a epidemiologia. Salvador: APCE/Abrasco; 1992.

9. Silva MAM. Trabalho e trabalhadores na região do "mar de cana e do rio de álcool". Agrária 2005; 2:2-39.

10. Pedraz MV. Estilo de vida saludable e ideología: dialéctica de la diferencia. Salud Pública M ex 2007; 49:388-389.

11. Rangel-S ML. Comunicação no controle de risco à saúde e segurança: uma abordagem interdisciplinar. Cien Saude Colet 2007; 12:1375-1385.

12. Campos $P$, Saguy $A$, Ernsberguer $P$, Oliver $E$, Gaesser G. The epidemiology of overweight and obesity: public health crisis or moral panic?. Int J Epidemiol 2006; 35:55-60.

13. Fraga $A B$. Exercício da informação: governo dos corpos no mercado da vida ativa. Campinas: Autores Associados; 2006.

14. Bauman Z. M odernidade e ambivalência. Rio de Janeiro: Zahar; 1999.

15. Castells M . A sociedade em rede. A era da informação: economia, sociedade e cultura. Vol. 1. $7^{\text {a }}$ ed. São PauIo: Paz e Terra; 2003.

16. Freitas $\mathrm{CM}$. Veneno e antídoto: ciência, tecnologia e os riscos para o homem. Hist. cienc. saude-M anguinhos1996; 3:505-522.

17. M arques MB. Saúde Pública, ética e mercado no entreato de dois séculos. São Paulo: Brasiliense; 2005.

18. M ieth D. A ditadura dos genes: a biotecnologia entre a viabilidade técnica e dignidade humana. Petrópolis: Vozes; 2003.

19. Costa JF. 0 vestígio e a aura: corpo e consumismo na moral do espetáculo. Rio de Janeiro: Garamond; 2004

20. Sfez L. A saúde perfeita: crítica a uma nova utopia. São Paulo: Unimarco/Loyola; 1995.

21. Vaz P, Carvalho CS, Pombo M. Risco e sofrimento evitável: a imagem da polícia no noticiário de crime. E-Compós [periódico na Internet]. 2005 dez [acessado 2007 jan 12];4:[cerca de 22 p.]. Disponível em: http://www.compos.com.br/e-compos

22. Barreto ML. Comentário: Tecnologia em saúde e 0 sempre tênue equilíbrio entre riscos e benefícios. Rev. Saude Publica 2006; 40:397-399.

23. Lupton $D$, Chapman $S$. A healthy lifestyle might be the death of you: discourses on diet, cholesterol control and hearth disease in the press and among the lay people. Sociol Health IIIness 1995; 17:477-494.

24. Illich I. A expropriação da saúde: nêmesis da medicina. $5^{\text {a }}$ ed. Rio de Janeiro: Forense; 1982. 
25. Escosteguy AC, Jacks N. Comunicação e recepção. São Paulo: Hacker; 2005.

26. Canclini NG. Culturas híbridas: estratégias para entrar e sair da modernidade. São Paulo: Edusp; 1997.

27. Deleuze G. Conversações. São Paulo: Editora 34; 1992.

28. Costa R. Sociedade de controle. São Paulo Perspec 2004; 18:161-167.

29. Vaz P. Risco e justiça. In: Calomeni TCB, organizador. M ichel Foucault: entre o murmúrio e a palavra. Campos: Editora Faculdade Direito de Campos; 2004. p. 101-131.

30. Foucault M. A ordem do discurso. $11^{\text {a }}$ ed. São Paulo: Loyola; 2004.

31. Fairclough N. Discurso e mudança social. Brasília: Editora UnB; 2001.

32. Robertson A. Biotechnology, political rationality and discourses on health. Health 2001; 59:293-309.

33. Sibilia P. 0 homem pós-orgânico: corpo, subjetividades e tecnologias digitais. Rio de Janeiro: Relume Dumará; 2003.

34. M oraes IHS. Informação em saúde: um olhar genealógico. In: M oraes IHS. Política, tecnologia e informação em saúde: a utopia da emancipação. Salvador: Casa da Saúde; 2002. p. 15-46.

35. Gastaldo D. É a educação em saúde 'saudável'? Repensando a educação em saúde através do conceito de bio-poder. In: M ercado FJ, Gastaldo D, Calderón $\mathrm{C}$, organizadores. Paradigmas y diseños de la investigación cualitativa en salud. Guadalajara: Universidad de Guadalajara; 2002. p. 345-373.

36. Petersen $A$, Lupton $D$. The new public health: health and self in the age of risk. London: Sage; 2000.

37. Campos GWSC. Reforma da reforma: repensando a saúde. 2a ed. São Paulo: Hucitec; 1997.

38. Brasil. Ministério da Saúde. Agita Brasil: programa nacional de promoção da atividade física. Brasília: Ministério da Saúde; 2002

39. Fraga AB. A boa forma de João e o estilo de vida de Fernanda. In: Louro GL, Neckel JF, Goellner SV organizadores. Corpo, gênero e sexualidade. Petrópolis: Vozes; 2003. p. 95-107.

40. Soares Neto JFP. A saúde modificada: criatividade, espontaneidade e satisfação na experiência corporal contemporânea [tese]. Rio de Janeiro (RJ): IM SUERJ; 2005.
41. Certeau M. Invenção do cotidiano: artes de fazer . Vol. 1. $5^{a}$ ed. Petrópolis: Vozes; 2000.

42. Le Breton D. A sociologia do corpo. $2^{\text {a }}$ ed. Petrópolis: Vozes; 2007.

43. Couto ES. O saudável e o doente na cibercultura. In: Louro GL, Neckel JF, Goellner SV, organizadores. Corpo, gênero e sexualidade. Petrópolis: Vozes; 2003. p. 172-186.

44. Nogueira RP. Higiomania: a obsessão com a saúde na sociedade contemporânea. In: Vasconcelos EM , organizador. A saúde nas palavras e nos gestos: reflexões da rede educação popular e saúde. São Paulo: Hucitec; 2001. p. 63-72.

45. Vaz P. 0 inconsciente artificial. São Paulo: Unimarco; 1997.

46. Couto ES. 0 homem-satélite: estética e mutações do corpo na sociedade tecnológica. Ijuí: Ed. Unijuí; 2000.

47. Novaes JV. 0 intolerável peso da feiúra: sobre as mulheres e seus corpos. Rio de Janeiro: PUC/Garamond; 2006.

48. Gomes IM, Pich S, Vaz AF. Sobre algumas vissitudes de noção de saúde na sociedade dos consumidores. Rev Bras Ciênc Esporte 2006; 27:137-151.

49. Canguilhem G. O normal e o patológico. Rio de Janeiro: Forense U niversitária; 1990.

50. Foucault M. Vigiar e punir. Petrópolis: Vozes; 1987.

51. Foucault M. História da sexualidade I - a vontade de saber. 13a ed. Rio de Janeiro: Graal; 1999.

52. Segurado R. Sociedade de controle: o bio-midiáticopoder [tese]. São Paulo (SP): Pontifícia Universidade Católica de São Paulo; 2002.

53. Van Loon J. Risk and technological culture: towards a sociology of virulence. London: Routledge; 2002.

54. Deleuze G, Guattari F. M il platôs: capitalismo e esquizofrenia. Vol. 1. São Paulo: Editora 34; 2000.

55. Silva AM . Corpo, ciência e mercado. Campinas: Autores Associados; 1999.

Artigo apresentado em 12/07/2008

Aprovado em 29/12//2008 